\title{
Inorganic Nitrile Halides in the Synthesis of Halogen-, Nitro- and Halogenated Nitro-Products
}

\author{
Yulia Yu Miroshnichenko ${ }^{a, b}$, \\ Anna G. Yarkova ${ }^{a}$, Irina A. Perederina ${ }^{a}$, \\ Elena N. Tveryakova ${ }^{a}$, Olga A. Golubina*a, \\ Elena A. Anisimova a and Galina A. Zholobova ${ }^{a}$ \\ ${ }^{a}$ Siberian State Medical University \\ Tomsk, Russian Federation \\ ${ }^{b}$ Tomsk Polytechnic University \\ Tomsk, Russian Federation
}

\begin{abstract}
Inorganic nitrile halides have been studied theoretically by quantum-chemical approach and experimentally in the reactions of halogenation, nitration and nitro halogenation of aromatic compounds and alkynes. The generation of nitrile halides was eventually proved can be can be carried out using the iodine system (alkali metal halides) in the presence of alkali metal nitrates in an acetic acid medium. It has been found that the reaction can give the products of iodination, nitration, nitro halogenation, as well as products of cyclization, and oxidation depending on the nature of the halogen. To predict the products of reaction theoretical quantum-chemical calculations for intermediate particles - nitrile halides using the standard Gaussian-03 software package were carried out. The possibility of $\mathrm{NO}_{2} \mathrm{Hal}$ formation was approved from quantum calculations. Furthermore the geometry of $\mathrm{NO}_{2} \mathrm{Hal}$ particles and mechanism of their homo- or heterolytic decay were represented.
\end{abstract}

Keywords: nitrile halides, halogenation, nitration, nitro halogenation, quantum - chemical calculations, geometry of nitrile halides particles, thermodynamics data of nitrile halides. 


\title{
Неорганические нитрилгалогениды \\ в синтезе галоген-, нитро- и галогеннитропродуктов
}

\author{
Ю. Ю. Мирошниченко ${ }^{a, 0}$, А. Г. Яркова ${ }^{a}$, \\ И.А. Передерина ${ }^{a}$, Е.Н. Тверякова ${ }^{a}$, \\ О.А. Голубина ${ }^{a}$ Е.А. Анисимова ${ }^{\text {, }}$, А. А. Жолобова ${ }^{a}$ \\ ${ }^{a}$ Сибирский государственный медиџинский университет \\ Российская Федерация, Томск \\ ${ }^{6}$ Томский политехнический университет \\ Российская Федерации, Томск
}

\begin{abstract}
Аннотация. Проведено теоретическое и экспериментальное изучение неорганических нитрилгалогенидов в реакциях галогенирования, нитрования и нитрогалогенирования аренов и алкинов. Показано, что при использовании системы $\mathrm{I}_{2}\left(\mathrm{Hal}^{-}\right)$в присутствии нитратов щелочных металлов в среде уксусной кислоты возможно образование нитрилгалогенидов. В зависимости от природы галогенида получены продукты йодирования, нитрования, нитрогалогенирования, циклизации, окисления органических субстратов. Для осуществления направленного синтеза проведены теоретические квантово-химические расчеты промежуточных частиц нитрилгалогенидов - с использованием стандартного пакета программ Gaussian-03. Расчет показал возможность образования частиц $\mathrm{NO}_{2} \mathrm{Hal}$, их геометрию и распад по гомо- или гетеролитическому механизму.
\end{abstract}

Ключевые слова: нитрилгалогениды, галогенирование, нитрование, нитрогалогенирование, квантово-химические расчеты, геометрия нитрилгалогенидов, термодинамические характеристики нитрилгалогенидов.

Цитирование: Мирошниченко, Ю. Ю. Неорганические нитрилгалогениды в синтезе галоген-, нитрои галогеннитропродуктов / Ю. Ю. Мирошниченко, А. Г. Яркова, И. А. Передерина, Е. Н. Тверякова, О. А. Голубина, Е. А. Анисимова, Г. А. Жолобова // Журн. Сиб. федер. ун-та. Химия, 2021, 14(1). С. 100-110. DOI: 10.17516/1998-2836-0220

\section{Введение}

Нитрилгалогениды представляют интерес для синтеза, так как являются потенциальными галогенирующими, нитрующими и нитрогалогенирующими реагентами. Нитрилгалогениды, галогениды нитрония - общепринятые тривиальные названия молекул $\mathrm{NO}_{2} \mathrm{~F}, \mathrm{NO}_{2} \mathrm{Cl}, \mathrm{NO}_{2} \mathrm{Br}$, $\mathrm{NO}_{2} \mathrm{I}$.

Соединения $\mathrm{NO}_{2} \mathrm{~F}, \mathrm{NO}_{2} \mathrm{Cl}, \mathrm{NO}_{2} \mathrm{Br}$ известны как индивидуальные вещества. Образование $\mathrm{NO}_{2}$ в в растворе ранее не было доказано, хотя исключить появление этой реакционноспособной частицы в равновесных концентрациях в растворе in situ невозможно.

Нитрилхлорид как реагент наиболее доступен, его получают при взаимодействии хлорсульфоновой кислоты с азотистой кислотой с высоким выходом. В последнее время нитрил хлорид получают из хлортриметилсилана и ацетилнитрата [1-4]. Получение нитрилфторида 
по реакции фтора с $\mathrm{N}_{2} \mathrm{O}_{4}$ затруднено, требует специального аппаратурного оснащения и строгих мер соблюдения безопасности при работе с газами. Фтористый нитрил можно получить в реакции $\mathrm{SF}_{5} \mathrm{OF}$ с $\mathrm{NO}_{2}$, а также путем фторирования нитритов щелочных металлов или разложением при $200{ }^{\circ} \mathrm{C}$ фторнитрильных солей бора (кремния) в присутствии фтористого никеля. Образование $\mathrm{NO}_{2} \mathrm{Br}$ в реакции $\mathrm{NO}_{2} \mathrm{Cl}$ с $\mathrm{NaBr}$ было зафиксировано с помощью ИК-спектров [5]. Получение $\mathrm{NO}_{2} \mathrm{Br}$ происходит по реакции $\mathrm{N}_{2} \mathrm{O}_{5}$ и раствора $\mathrm{NaBr}$ с высокой концентрацией бромид-ионов, тогда как при низких концентрациях бромида реакция не идет. Образование нитрилбромида предполагают и в системах $\mathrm{NO}_{2}-\mathrm{Br}_{2}$ и $\mathrm{MeNO}_{2}-\mathrm{KBr}$ в $\mathrm{CF}_{3} \mathrm{COOH}(\mathrm{Me}$ - щелочные и щелочноземельные металлы). Образование нитрилйодида не исключают в системах $\mathrm{N}_{2} \mathrm{O}_{4}-\mathrm{I}_{2}$, $\mathrm{AgNO}_{2}-\mathrm{I}_{2}, \mathrm{NaNO}_{2}-\mathrm{I}_{2}$ в этилацетате с водой и этиленгликолем, $\mathrm{NaNO}_{3}-\mathrm{I}_{2}(\mathrm{KI})$ в уксусной кислоте [6].

Нитрилгалогениды применяют для функционализации органических соединений. Например, фтористый нитрил реагирует с перфторкетонами, образуя соответствующие нитраты. В работе [7] показано, что реакция EtOH с $\mathrm{NO}_{2} \mathrm{~F}$ в безводном MeCN в присутствии KF приводит к образованию этилнитрата с высоким выходом. Этот метод использовали для получения нитратов замещенных спиртов алифатического ряда. Таким образом, в этих работах доказано, что с органическими веществами нитрилфторид проявляет нитрующую активность.

Известно, что распад нитрилхлорида зависит от условий протекания реакции; так, при взаимодействии фенилацетилена и хлористого нитрила получают дихлорпроизводное и хлорнитропроизводное этилена. Присоединение протекает по свободнорадикальному механизму, но не исключена возможность ионного присоединения. Диссоциация нитрилхлорида может проходить в двух направлениях в зависимости от типа растворителя. По пути (А) в неполярных растворителях, а по пути (В) - в полярных:

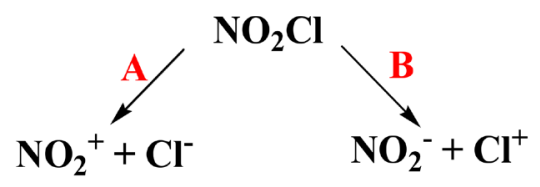

При присоединении $\mathrm{NO}_{2} \mathrm{Cl}$ к непредельным соединениям в полярных нуклеофильных растворителях реализуется ионный механизм (В). Таким образом, нитрилхлорид является чувствительным реагентом не только к условиям проведения реакции, но и к природе субстрата. Так, например, в реакции ароматических соединений с $\mathrm{MeCl} / \mathrm{MeNO}_{3}$ в трифторуксусной кислоте при добавлении воды доминирующей реакцией является хлорирование, тогда как без добавок $\mathrm{H}_{2} \mathrm{O}$ единственным продуктом является нитропроизводное. Влияние природы субстрата показано в работе [8], в которой данная закономерность подтверждена и с нитрилбромидом. Образующийся in situ нитрилбромид с ароматическими соединениями, содержащими сильно дезактивированные группы, вступает в реакцию бромирования, а с умеренно дезактивированными группами преобладает реакция нитрования. В работах $[9,10]$ подтверждена возможность образования нитрилфторида, нитрилхлорида, нитрилбромида. Авторы делают вывод на основании термодинамического расчета свободной энергии Гиббса процесса диссоциации с учетом анализа относительной (локальной) электрофильности нитрилгалогенидов и установливают 
зависимость электрофильной галогенирующей способности нитрилгалогенидов в ряду $\mathrm{NO}_{2} \mathrm{Br}$ $>\mathrm{NO}_{2} \mathrm{Cl}>\mathrm{NO}_{2} \mathrm{~F}$. Показано, что нитрилфторид наиболее подходящий реагент для проведения реакции нитрования с ароматическими субстратами.

Нитрилиодид - интермедиат, предположительно образующийся в системах $\mathrm{AgNO}_{2}-\mathrm{I}_{2}, \mathrm{I}_{2}-$ $\mathrm{NO}_{3}{ }^{-}-\mathrm{CF}_{3} \mathrm{COOH}, \mathrm{I}_{2}-\mathrm{NO}_{3}{ }^{-}-\mathrm{CH}_{3} \mathrm{COOH}, \mathrm{I}_{2}-\mathrm{HNO}_{2}-\mathrm{AcOH}-\mathrm{HClO}_{4}, \mathrm{KI}-\mathrm{HNO}_{2}-\mathrm{H}_{2} \mathrm{SO}_{4}-\mathrm{H}_{2} \mathrm{O}$, $\mathrm{NH}_{4} \mathrm{NO}_{3}-\mathrm{I}_{2}-\mathrm{H}_{2} \mathrm{SO}_{4}-\mathrm{O}_{2}[2,11]$, в реакциях с ароматическими субстратами проявляет иодирующую активность. Основными продуктами в этих реакциях были йодарены.

В работе [3] с производными алкенов в системе $\mathrm{NaNO}_{2}-\mathrm{KI}-$ Oxоnе были получены нитроалкены. Отмечено влияние заместителей на выход продуктов. Так, производные стирола, содержащие электронодонорные группы, реагируют в системе $\mathrm{NaNO}_{2}-\mathrm{KI}-\mathrm{Oxone} \mathrm{c} \mathrm{высокими} \mathrm{вы-}$ ходами в отличие от субстратов с электроноакцепторными группами. В работе [4] предложена система $\mathrm{I}_{2}-\mathrm{tBuONO}_{2}-\mathrm{THF}$ для дифункционализации алкинов, в этих реакциях получают иоднитропроизводные алкенов.

Нами были проведены исследования, в которых система нитраты щелочных металлов / $\mathrm{I}_{2}$ (KI) в уксусной кислоте проявляет йоднитрующую способность по отношению к алкинам [6]. Данная система показала возможность строго направленного однореакторного йоднитрования кратных связей производных ацетилена. Кроме того, предложена схема механизма йодирования аренов и йоднитрования непредельных углеводородов, включающая цикл окислительновосстановительных реакций между йодом (йодидом) и нитрат-ионом в уксусной кислоте с образованием нитрилйодида:

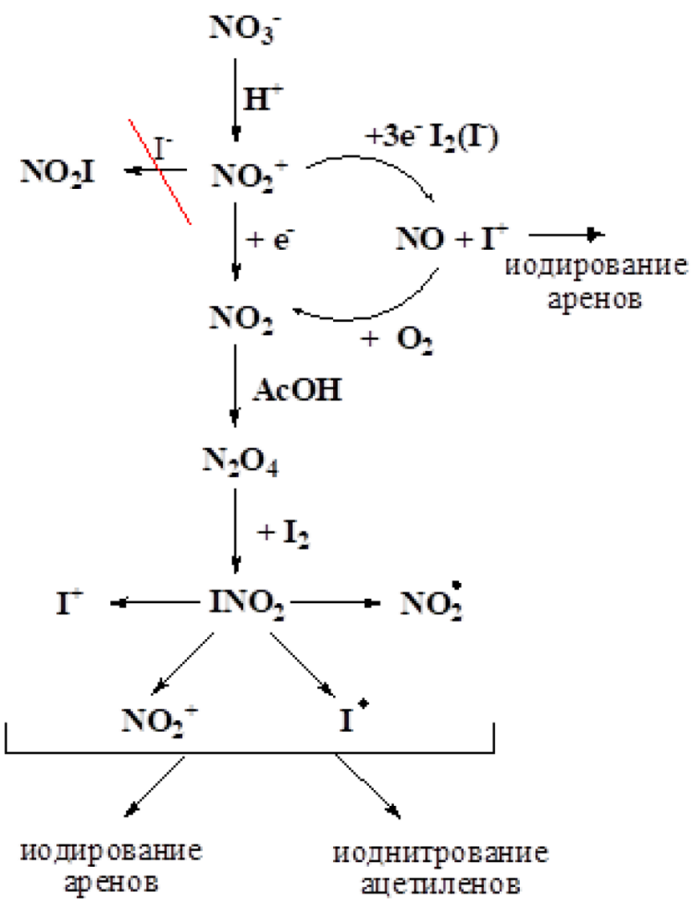

В случае алкенов реакция протекает с образованием нитросоединений из промежуточных йоднитроалканов, тогда как при йоднитровании алкинов выделены с высокими выходами иоднитроалкены. 


\section{Результаты и обсуждение}

Предложенная система нитраты щелочных металлов / $\mathrm{I}_{2}(\mathrm{KI})$ в уксусной кислоте является доступной и безопасной в органическом синтезе. Для изучения механизма реакций и экспериментального подтверждения образования нитрилгалогенидов in situ мы заменили йодид в изучаемой системе на другие галогениды (фторид-, хлорид-, бромид-) и провели реакции с 9-метилкарбазолом, так как данное соединение обладает повышенной активностью в реакциях электрофильного замещения. При использовании в системе $\mathrm{NO}_{3}^{-} / \mathrm{HAc}$ йода основным продуктом реакции был 3,6-дииод-9-метилкарбазол с высоким выходом. А при использовании йодида или бромида выделяли смесь продуктов галогенирования и нитрования. С фторидом или хлоридом в изучаемой системе были выделены только продукты нитрования. На основании полученных данных предположили образование нитрилгалогенидов в этих системах и их разную диссоциацию.

Для подтверждения механизма образования нитрилгалогенидов и доказательства влияния природы добавленных галогенидов (или иода) в системе $\mathrm{NO}_{3}{ }^{-} / \mathrm{HAc}$ при $85^{\circ} \mathrm{C}$ экспериментально определили концентрацию оксида азота (IV) (табл. 1). Для этого использовали стандартную методику улавливания газа $\left(\mathrm{NO}_{2}\right)$ пленочным хемосорбентом и фотометрическое определение $\mathrm{NO}_{2}{ }^{-}$-аниона.

Таблица 1. Количественное определение $\mathrm{NO}_{2}$ в системе $\mathrm{I}_{2}$ (или $\mathrm{Hal}^{-}{ }^{*}$ / $\mathrm{NO}_{3}{ }^{-}$в $\mathrm{HAc}$

Table 1. Quantitative determination of $\mathrm{NO}_{2}$ in the $\mathrm{I}_{2}$ (or $\left.\mathrm{Hal}^{-}\right)^{*} / \mathrm{NO}_{3}{ }^{-}$system in $\mathrm{HAc}$

\begin{tabular}{|c|c|c|c|c|}
\hline Реагент $\mathrm{NO}_{3}{ }_{3}^{-} / \mathrm{HAc}$ & Время реакции, ч & $\begin{array}{l}\text { Оптическая } \\
\text { плотность, D }\end{array}$ & С, мг/л & n, ммоль \\
\hline- & 1 & 0,12 & 0,021 & 0,04 \\
\hline- & 5 & 0,44 & 0,176 & 0,33 \\
\hline KI & 1 & 0,67 & 0,26 & 0,53 \\
\hline $\mathrm{KBr}$ & 1 & 0,7 & 0,28 & 0,57 \\
\hline $\mathrm{KCl}$ & 1 & 0,051 & 0,04 & 0,008 \\
\hline $\mathrm{NaF}$ & 1 & 0,097 & 0,097 & 0,019 \\
\hline $\mathrm{I}_{2}$ & 1 & 0,5 & 0,19 & 0,38 \\
\hline $\mathrm{I}_{2}$ & 5 & 1,5 & 0,63 & 1,26 \\
\hline
\end{tabular}

${ }^{*} \mathrm{Hal}=\mathrm{F}, \mathrm{Cl}, \mathrm{Br}, \mathrm{I}$.

Обнаружили, что природа галогенида определяет количество образующегося в системе $\mathrm{NO}_{2}$. Наиболее вероятный путь образования нитрилиодида и нитрилбромида протекает через ряд окислительно-восстановительных реакций:

$$
\begin{aligned}
& \left.6 \mathrm{I}^{-}(\mathrm{Br})^{-}\right)+2 \mathrm{NO}_{3}{ }^{-}+8 \mathrm{H}^{+}=3 \mathrm{I}_{2}\left(\mathrm{Br}_{2}\right)+2 \mathrm{NO}+4 \mathrm{H}_{2} \mathrm{O} ; \\
& 2 \mathrm{NO}+\mathrm{O}_{2}=2 \mathrm{NO}_{2} ; \\
& 2 \mathrm{NO}_{2}+\mathrm{I}_{2}=2 \mathrm{INO}_{2} .
\end{aligned}
$$


Окислительно-восстановительные реакции (1) и (2) известны и термодинамически возможны с большими отрицательными значениями изменения свободной энергии Гиббса.

При использовании йода, йодидов или бромидов выделяется оксида азота (IV) значительно больше, чем при использовании хлоридов или фторидов щелочных металлов (табл. 1) из-за отсутствия окислительно-восстановительных взаимодействий между хлорид-ионами, фторидионами и нитратами щелочных металлов в кислой среде. Энергия Гиббса этих реакций имеет положительные значения. Однако может происходить реакция $\mathrm{X}^{-}+\mathrm{NO}_{2}{ }^{+} \rightarrow \mathrm{XNO}_{2}$ по пути ионного связывания. Известно [8], что нитрилхлорид и нитрилфторид являются стабильными частицами. Тогда как нитрилбромид и нитрилиодид существуют в равновесии с $\mathrm{Br}_{2}$ или $\mathrm{I}_{2}$ и $\mathrm{NO}_{2}$. Мы проверили растворимость солей галогенидов щелочных металлов в уксусной кислоте, для этого растворили 1 ммоль галогенида в 5 мл уксусной кислоты и нагрели до $85^{\circ} \mathrm{C}$. Экспериментальные данные растворимости солей (KI, $\mathrm{KBr}, \mathrm{KCl}, \mathrm{NaF}$ ) в уксусной кислоте имеют близкие значения (от 0,175 до 0,190 моль/л), а количество $\mathrm{NO}_{2}$ в зависимости от того, какой в реакционной системе галогенид, резко меняется. Следовательно, наше предположение о том, что образование нитрилфторида и нитрилхлорида идет по пути ионного связывания галогенида и нитронийкатиона не исключает образования нитрилгалогенидов в изучаемых нами системах.

Для анализа строения и реакционной способности ряда нитрилгалогенидов $\mathrm{HalNO}_{2}$ $(\mathrm{Hal}=\mathrm{F}, \mathrm{Cl}, \mathrm{Br}, \mathrm{I})$ проведен квантово-химический расчет с использованием стандартного пакета программ Gaussian-03. Для проведения теоретических исследований применили метод функционала плотности (DFT) B3LYP с полноэлектронным базисным набором DGDZVP [12, 13]. Данный метод широко используется в последние годы для расчетов соединений, содержащих атомы V периода, включая йод. Метод позволяет получить точные результаты в предсказании геометрических и термодинамических характеристик $[14,15]$. Для изучения природы связей в молекулах нитрилгалогенидов использовали приближение натуральных орбиталей связи (NBO).

Модели рассчитанных молекул были полностью оптимизированы, а отсутствие мнимых частот колебаний подтверждает их стационарный характер. Расчеты геометрии и термодинамических величин в растворе проведены вышеуказанными методами с использованием модели поляризованного континуума (PCM) [16], в качестве растворителя был выбран ацетонитрил, близкий по полярности к уксусной кислоте. Энергии рассчитанных соединений скорректированы с учетом нулевой колебательной энергии (ZPVE) и приведены к стандартным условиям (298,15 K, 1 атм) с использованием термической поправки к энтальпии и свободной энергии.

На основании проведенных квантово-химических расчетов построены модели молекул нитрилгалогенидов (рис. 1, табл. 2), определено распределение зарядов NBO и направление вектора дипольного момента. Длина связи $\mathrm{Hal}-\mathrm{N}$ в ряду галогенов $(\mathrm{F}-\mathrm{Cl}-\mathrm{Br}-\mathrm{I})$ закономерно увеличивается, а индекс Виберга, который показывает кратность связи, уменьшается. Значит, среди нитрилгалогенидов связь I - N наименее прочная и более склонна к разрыву.

Дефицит электронной плотности на атоме галогена в соединениях $\mathrm{HalNO}_{2}$ растет при переходе от фтора к йоду в соответствии с электроотрицательностью атомов галогенов, а положительный заряд на атоме азота нитрогруппы снижается. Электронная плотность связи $\mathrm{F}-\mathrm{N}$ в молекуле $\mathrm{FNO}_{2}$ сильно смещена к атому фтора и дает возможность использования нитрилфторида в качестве нитрующего реагента [13].

$$
-105-
$$




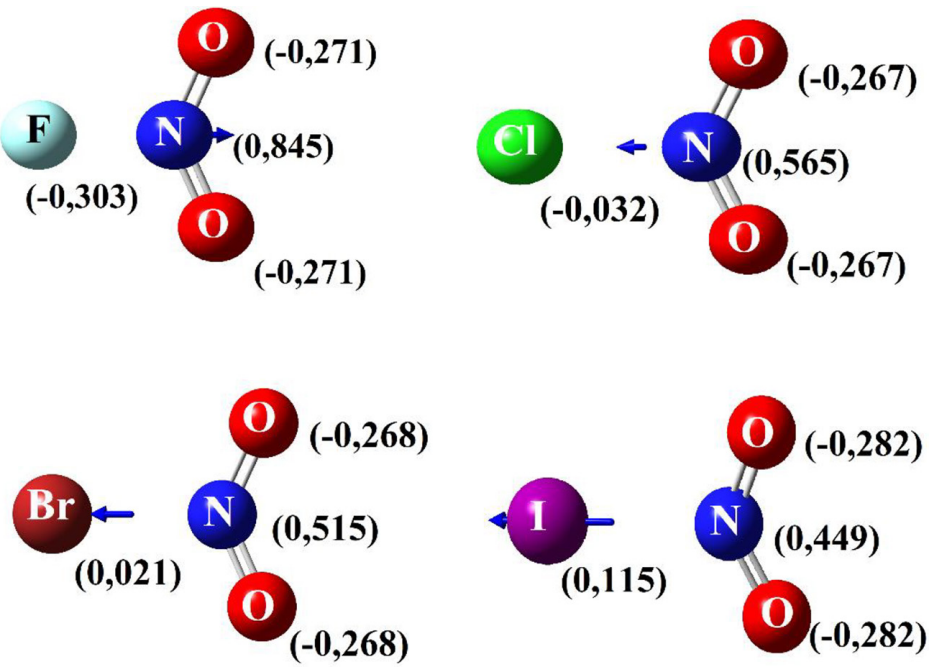

Рис. 1. Модели молекул $\mathrm{NO}_{2} \mathrm{Hal}$, оптимизированных методом B3LYP/dgdzvp

Fig. 1. Models of $\mathrm{NO}_{2} \mathrm{Hal}$ molecules optimized by the B3LYP/dgdzvp method

Таблица 2. Геометрия молекул $\mathrm{NO}_{2} \mathrm{Hal}$

Table 2. Geometry of $\mathrm{NO}_{2} \mathrm{Hal}$ molecules

\begin{tabular}{|c|c|c|c|c|c|c|c|c|}
\hline \multirow{2}{*}{ Hal } & \multirow{2}{*}{$\mu$} & \multirow{2}{*}{ 1, нм } & \multirow{2}{*}{$\mathrm{q}_{\mathrm{NBO}} \mathrm{Hal}$} & \multirow{2}{*}{$\mathrm{q}_{\mathrm{NBO}} \mathrm{N}$} & \multirow{2}{*}{$\Delta \mathrm{q}$} & $\omega(\mathrm{Hal})$ & $\omega(\mathrm{N})$ & \multirow{2}{*}{ w N-Hal } \\
\hline & & & & & & \multicolumn{2}{|c|}{$\%$} & \\
\hline $\mathrm{F}$ & $-0,5014$ & 1,478 & $-0,303$ & 0,845 & 1,148 & 61,8 & 38,2 & 0,6853 \\
\hline $\mathrm{Cl}$ & 0,2899 & 1,900 & $-0,032$ & 0,565 & 0,597 & 44,1 & 55,9 & 0,6969 \\
\hline $\mathrm{Br}$ & 0,6442 & 2,067 & 0,021 & 0,515 & 0,494 & 40,4 & 59,6 & 0,6612 \\
\hline I & 1,3373 & 2,286 & 0,115 & 0,449 & 0,334 & 34,8 & 65,2 & 0,6295 \\
\hline
\end{tabular}

Примечание: $\mu$ - дипольный момент молекулы; 1 - длина связи Нal-N, нм; w - индекс Виберга связи На1-N; qNво - заряд на атоме атоме, рассчитанный NBO; $\omega$ - распределение (доля) электронной плотности связи Нal-N, \%

Связи $\mathrm{Cl}-\mathrm{N}$ и $\mathrm{Br}-\mathrm{N}$ наименее полярны среди нитрилгалогенидов с незначительным смещением электронной плотности ( $\omega, \%)$ к атому азота (табл. 2$)$, что позволяет использовать их не только как ионные, но и как радикальные реагенты в органическом синтезе. В молекуле $\mathrm{INO}_{2}$ электронная плотность связи I - $\mathrm{N}$ сильно смещена к нитрогруппе, поэтому йод может выступать в качестве электрофила.

Для нитрилгалогенидов выполнены расчеты термодинамических параметров гомолиза и гетеролиза связей Hal-N в нитрилгалогенидах методом B3LYP/dgdzvp, данные которых приведены в табл. 3.

Из термодинамических расчетов гомолиза и гетеролиза нитрилгалогенидов следует, что легче всего разрывается связь в нитрилйодиде. Очевидно, связь I - N в молекуле нитрилйодида поляризуется с образованием I+ под влиянием субстратов с выраженным нуклеофильным характером (карбазол, анизол и т. п.). А для непредельных соединений наиболее термодинамически выгоден радикальный распад с образованием частиц I• и • $\mathrm{NO}_{2}$ (табл. 3).

$$
-106-
$$


Таблица 3. Термодинамические параметры гомолиза и гетеролиза $\mathrm{NO}_{2} \mathrm{Hal}$ (метод B3LYP/dgdzvp)

Table 3. Thermodynamics parameters of $\mathrm{NO}_{2} \mathrm{Hal}$ homolysis and heterolysis (B3LYP/dgdzvp method)

\begin{tabular}{|c|c|c|c|c|}
\hline \multirow{2}{*}{ Hal } & $\Delta \mathrm{G}$ & $\Delta \mathrm{H}$, & \multirow{2}{*}{$\Delta \mathrm{S}$ кал/моль· } & \multirow{2}{*}{$\begin{array}{c}\Delta \mathrm{G} \text { раствор, ккал/ } \\
\text { моль }\end{array}$} \\
\hline & \multicolumn{2}{|c|}{ ккал/моль } & & \\
\hline \multicolumn{5}{|c|}{ Гомолиз $\mathrm{Hal}-\mathrm{NO}_{2} \rightarrow \mathrm{Hal}^{\bullet}+\mathrm{NO}_{2}{ }^{\circ}$} \\
\hline $\mathrm{F}$ & 43 & 51 & 30 & 45 \\
\hline $\mathrm{Cl}$ & 22 & 30 & 29 & 23 \\
\hline $\mathrm{Br}$ & 17 & 25 & 28 & 18 \\
\hline I & 11 & 19 & 28 & 13 \\
\hline \multicolumn{5}{|c|}{ Гетеролиз $\mathrm{Hal}-\mathrm{NO}_{2} \rightarrow \mathrm{Hal}^{+}+\mathrm{NO}_{2}^{-}$} \\
\hline $\mathrm{F}$ & $=$ & $=$ & $=$ & $=$ \\
\hline $\mathrm{Cl}$ & 262 & 270 & 27 & 188 \\
\hline $\mathrm{Br}$ & 256 & 234 & 26 & 156 \\
\hline I & 183 & 191 & 26 & 118 \\
\hline \multicolumn{5}{|c|}{ Гетеролиз $\mathrm{Hal}-\mathrm{NO}_{2} \rightarrow \mathrm{Hal}^{-}+\mathrm{NO}_{2}{ }^{+}$} \\
\hline $\mathrm{F}$ & 147 & 151 & 15 & 63 \\
\hline $\mathrm{Cl}$ & 122 & 114 & 14 & 41 \\
\hline $\mathrm{Br}$ & 104 & 109 & 14 & 42 \\
\hline I & 100 & 105 & 13 & 44 \\
\hline
\end{tabular}

Изучив термодинамику процессов диссоциации нитрилгалогенидов, установили, что электрофильная галогенирующая активность уменьшается в ряду нитрилгалогенидов от $\mathrm{Cl}$ к I, а свободнорадикальная реакционная способность возрастает от $\mathrm{FNO}_{2}<\mathrm{ClNO}_{2}<\mathrm{BrNO}_{2}<\mathrm{INO}_{2}$. Квантово-химические расчеты позволили подтвердить схему механизма йодирования аренов и йоднитрования непредельных углеводородов и объяснить разную природу продуктов в реакциях с нитрилйодидом, а также уточнить схемы механизмов реакций галогенирования аренов и йоднитрования производных алкинов.

Для этого мы рассчитали термодинамические характеристики реакции (3):

$$
2 \mathrm{NO}_{2}+\mathrm{I}_{2}=2 \mathrm{INO}_{2} \text {. }
$$

Определили, что свободная энергия Гиббса реакции в растворе равна +11 ккал/моль, а энтальпия +1 ккал/моль, что подтверждает равновесный характер реакции (3). Дальнейший распад нитрилйодида зависит от природы субстрата; так, с ароматическими соединениями идет образование $\mathrm{I}^{+}$, а в реакциях с производными алкинов образуются радикальные частицы.

Для реакций взаимодействия нитрилйодида с анизолом с образованием п-йоданизола (реакция 4), а также реакции взаимодействия нитрилйодида с дифенилацетиленом (реакции 5 и 6) получили значения свободной энергии Гиббса, энтропии и энтальпии (табл. 4).

$$
{ }^{\mathrm{O}} \mathrm{CH}_{3}+\mathrm{I}-\mathrm{NO}_{2} \longrightarrow{ }^{\mathrm{O}} \mathrm{CH}_{3}+\mathrm{H}_{-} \mathrm{NO}_{2}
$$




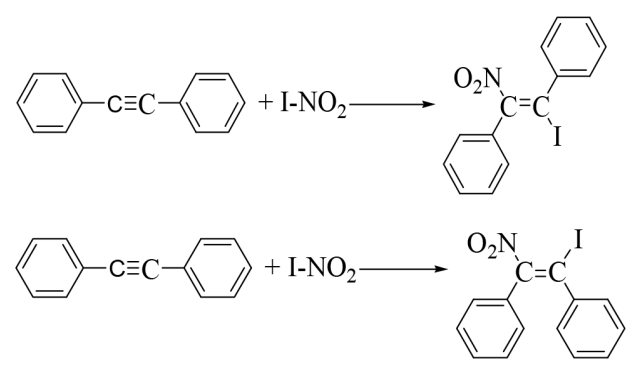

Квантово-химический расчет термодинамики реакций нитрилйодида с аренами и алкинами показывает возможность получения основных продуктов йодирования аренов или двойной функционализации алкинов.

При стандартных условиях свободная энергия Гиббса изучаемых реакций (46) (табл. 4) близка к нулю, что указывает на состояния химического равновесия. При комнат-

Таблица 4. Значения $\Delta \mathrm{G}, \Delta \mathrm{H}, \Delta \mathrm{S}$ для реакций (4-6)

Table 4. Values $\Delta \mathrm{G}, \Delta \mathrm{H}, \Delta \mathrm{S}$ for reactions (4-6)

\begin{tabular}{|c|c|c|c|c|}
\hline Реакция & $\Delta \mathrm{G}$ & $\Delta \mathrm{H}$ & $\Delta \mathrm{S}$ & $\Delta \mathrm{G} \mathrm{p}-\mathrm{p}$ \\
\hline & \multicolumn{2}{|c|}{ ккал/моль } & ккал/моль*K & ккал/моль \\
\hline$(4)$ & -3 & -2 & -1 & -6 \\
\hline$(5)$ & -11 & -25 & -46 & -12 \\
\hline$(6)$ & -10 & -25 & -49 & -13 \\
\hline
\end{tabular}

ной температуре изучаемые реакции практически не протекают, для образования продуктов необходимо нагревание от 60 до $85^{\circ} \mathrm{C}$. При температуре $85^{\circ} \mathrm{C}$ получены п-йоданизол (реакция 4) с выходом $92 \%$. Выходы продуктов составили в реакции (5) Е - йоднитростильбена $44 \%$, а в реакции (6) Z - иоднитростильбена $12 \%$.

\section{Вывод}

Экспериментально и теоретически доказано образование нитрилйодида в системах $\mathrm{I}_{2}$ (или I-) / нитраты щелочных металлов в уксусной кислоте. Установлено, что образующийся нитрилйодид обладает йодирующей способностью по отношению к ароматическим соединениям.

Квантово-химическим расчетом подтвержден механизм получения нитрилгалогенидов. Изучены химические свойства, установлена возможность их распада по гомо- и гетеролитическому пути в зависимости от условий реакции и природы субстрата.

Составлен сравнительный ряд электрофильной галогенирующей активности нитрилгалогенидов по отношению к аренам и свободнорадикальной реакционной способности по отношению к алкинам.

Полученные теоретические и экспериментальные данные позволят прогнозировать поведение неорганических нитрилгалогенидов в заданной реакционной массе, что даст возмож- 
ность вести направленный синтез при получении продуктов галогенирования, нитрования или двойной функционализации - галогеннитрования.

\section{Список литературы / References}

1. Abdukarim H.A. Mohammed, Nagendrappa G. Generation of nitryl chloride from chlorotrimethylsilane-acetyl nitrate reaction: A one-pot preparation of gem-chloronitro compounds from oximes. Journal Chemical Sciences 2010. Vol. 122 (4), P. 571-577.

2. Prebil R., Stavber S. Aerobic oxidative $\alpha$-iodination of carbonyl compounds using molecular iodine activated by a nitrate-based catalytic systemю. Tetrahedron 2014, Vol. 55 (41), P. 5643-5647.

3. Hlekhlai S., Samakkanad N., Sawangphon T., Pohmakotr M., Reutrakul V., Soorukram D., Jaipetch T., Kurakkan C. Oxone/KI-Mediated Nitration of Alkenes and Alkynes: Synthesis of Nitroand $\beta$-Iodonitro-Substituted Alkenes. European journal of organic chemistry 2014, Vol. 33, P. 74337442.

4. Fan Yu., Zhou B., Chen K., Wang B., Li X., X. Xu A Facile Synthesis of $\beta$-Iodonitro Alkenes via Iodonitration of Alkynes with tert-Butyl Nitrite and Iodine. Synlett 2017. Vol. 28 (13), P. 1657-1659.

5. Mitroo D., Gill T., Haas S., Pratt K. A., Gaston C. J. $\mathrm{ClNO}_{2}$ Production from $\mathrm{N}_{2} \mathrm{O}_{5}$ Uptake on Saline Playa Dusts: New Insights into Potential Inland Sources of $\mathrm{ClNO}_{2}$. Environmental Science and Technology 2019. Vol.53 (13), P. 7442-7452.

6. Yusubov M. S., Perederina I. A., Kulmanakova Yu. Y., Filimonov V.D., Chi K.-W. Reactions of alkynes with iodine and potassium iodide in acetic acid in the presence of nitrates simple synthesis of 1-iodo-2nitroalkenes. Russian Journal of Organic Chemistry. 1999. Vol. 35 (9), P. 1264-1272.

7. Федоров Б.С., Еременко Л.Т. Нитрование спиртов фтористым нитрилом. Изв. АH. Ceрия хим. 1997. № 5. C. 1059-1060. [Fedorov B. S., Eremenko L. T. Nitration of alcohols fluorinated nitrile. Izv. AN. Seriya khim. 1997. № 5, P. 1059-1060. (In Russ.)]

8. Cherpakov A.V., Makhonkov D. I., Rodmin M. A., Beletskaya I. P. Catalytic and stoichiometric bromination of aromatic compounds in aqueous trifluoroacetic acid in the presence of nitrogencontaining dyes. Journal of Organic Chemistry 1988. Vol. 24(2), P. 248-255.

9. Крылов Е.Н., Цветкова Д. В. Теоретический анализ активности нитроний-галогенидов в реакциях ароматического нитрования и галогенирования. Вестник Ивановского государственного университета. Серия: Естественные, общественные науки 2017. № 2. С. 54-62. [Krylov E. N., Tsvetkova D. V. Theoretical analysis of the activity of nitronium halides in the reactions of aromatic nitration and halogenation. Bulletin of Ivanovo state University. Series: Natural and social Sciences 2017. N2, P. 54-62. (In Russ.)]

10. Peterson K.A., Francisco J. S. An ab initio investigation of the ground and low-lying singlet and triplet electronic states of $\mathrm{XNO}_{2}$ and $\mathrm{XONO}(\mathrm{X}=\mathrm{Cl}, \mathrm{Br}$, and I). Journal of Chemical Physic 2014. Vol. 140 (4).

11. Suo C., Xiaowei Z., Hui Z., Xiaohong G., Xiangguo H. Switchable Synthesis of Iodoalkynes and Diiodoalkenes from Terminal Alkynes. Chinese Journal Organic Chemistry 2018. Vol. 38(5), P. 1172-1176.

12. Parra R.D. Metal-ion binding via a cyclic network of intramolecular halogen-bonded interactions: a theoretical study. Molecular Physics. An International Journal at the Interface Between Chemistry and Physics 2016. Vol. 114(9), P. 1495-1493.

$$
-109-
$$


13. Yurieva A. G., Poleshchuk O. Kh., Filimonov V.D. Comparative analysis of a full-electron basis set and pseudopotential for the iodine atom in DFT quantum-chemical calculations of iodinecontaining compounds. Journal of structural chemistry 2008. Vol. 49(3), P. 548-552.

14. Зверева М.Н., Полещук О.Х., Яркова А.Г., Долгушина Л. В., Горностаев Л. М. Исследование механизма реакции аминирования методом функционала плотности. Современные наукоемкие технологии 2010. № 6. С. 7-15. [Zvereva M.N., Poleshchuk O.H., Yarkova A. G., Dolgushina L. V., Gornostaev L. M. Investigation of the mechanism of the amination reaction by the density functional method. Sovremennye naukoyomkie tekhnologii 2010. № 6, P. 7-15. (In Russ.)]

15. Андриенко О.С., Гусев А. Л., Егоров Н. Б.,Жерин И. И., Казарян М. А., Обмуч К. В., Полещук О.Х. Исследование свойств изотопов серы методами колебательной спектроскопии и квантовой химии. Альтернативная энергетика и экология 2013. № 5-1, С. 75-81. [Andrienko O.S., Gusev A. L., Egorov N. B., Zherin I. I., Kazaryan M.A., Obmuch K. V., Poleshchuk O. H. Investigation of the properties of sulfur isotopes by vibrational spectroscopy and quantum chemistry. Al'ternativnaya energetika i ekologiya 2013. № 5-1, P. 75-81. (In Russ.)].

16. Solimannejad M., Ramezan V., Trujillo C., Alkorta I., Sánchez-Sanz G., Elguero J., Competition and Interplay between $\sigma$-Hole and $\pi$-Hole Interactions: A Computational Study of 1:1 and 1:2 Complexes of Nitryl Halides $\left(\mathrm{O}_{2} \mathrm{NX}\right)$ with Ammonia. Journal of Physical Chemictry 2012, Vol. 116 (21), P. 5199-5206. 